\title{
Potential Effects on Cardiorespiratory and Metabolic Status After a Concurrent Strength and Endurance Training Program in Diabetes Patients - a Randomized Controlled Trial
}

Daniela Bassi ${ }^{1}$, Renata Gonçalves Mendes ${ }^{1}$, Vivian Maria Arakelian², Flávia Cristina Rossi Caruso ${ }^{1}$, Ramona Cabiddu', José Carlos Bonjorno Júnior ${ }^{2,3}$, Ross Arena ${ }^{4,5}$ and Audrey Borghi-Silva ${ }^{1,2^{*}}$

\begin{abstract}
Background: Concurrent aerobic and resistance training (CART) programs have been widely recommended as an important strategy to improve physiologic and functional performance in patients with chronic diseases. However, the impact of a personalized CART program in patients with type 2 diabetes (T2D) requires investigation. Therefore, the primary aim of the current study is to investigate the impact of CART programs on metabolic profile, glycemic control, and exercise capacity in patients with diabetes.

Methods: We evaluated 41 subjects with T2D (15 females and 19 males, $50.8 \pm 7$ years); subjects were randomized into two groups; sedentary (SG) and CART (CART-G). CART was performed over 1.10-h sessions (30-min aerobic and 30-min resistance exercises) three times/week for 12 weeks. Body composition, biochemical analyses, peripheral muscular strength, and cardiopulmonary exercise testing were primary measurements.

Results: The glycated hemoglobin HbA1c (65.4 \pm 17.9 to $55.9 \pm 12.7 \mathrm{mmol} / \mathrm{mol})$, cholesterol $(198.38 .1 \pm 50.3$ to 186 . $8 \pm 35.1 \mathrm{mg} / \mathrm{dll}$ ), and homeostasis model assessment insulin resistance (HOMA-IR) (6.4 \pm 6.8 to $5.0 \pm 1.4)$ decreased in the CART-G compared to the SG. Although body weight did not significantly change after training, skinfold measurement indicated decreased body fat in the CART-G only. CART significantly enhanced muscle strength compared to the SG $(p<0.05)$. CART was also associated with significant increase in peak oxygen uptake and maximal workload compared to the SG $(p<0.05)$.
\end{abstract}

Conclusions: These data support CART as an important strategy in the treatment of patients with T2D, producing both physiologic and functional improvements.

Trial Registration: Ensaiosclinicos.gov.br, RBR492q8z

Keywords: Diabetes mellitus, Concurrent training program, HbA1c, Oxygen uptake, Metabolic profile

\footnotetext{
*Correspondence: audrey@ufscar.br

${ }^{1}$ Cardiopulmonary Physiotherapy Laboratory, Physical Therapy Department,

Federal University of Sao Carlos, Rodovia Washington Luis Km 235, Sao

Carlos, SP, Brazil

${ }^{2}$ Department of Interunits of Bioengineer, University of São Paulo, São Paulo,

SP, Brazil

Full list of author information is available at the end of the article
} 


\section{Key Points}

- Concurrent aerobic and resistance training has important translational implications for the management of diabetic patients

- A 12-week supervised, individualized, and personalized concurrent aerobic and resistance training improves glycemic control, body composition, and functional capacity parameters, including oxygen uptake and muscle strength, in diabetic patients

- Changes in peak $\mathrm{VO}_{2}$ could predict $21 \%$ of the changes expected for HbA1c, which can explain the link between metabolic profile and exercise performance using a concurrent aerobic and resistance training program

\section{Background}

In Brazil, type 2 diabetes (T2D) currently assumes a prominent position among the non-communicable diseases, affecting 11.3 million people in 2011; projections indicate that this number is likely to triple by 2030 [1]. In view of this scenario, lifestyle interventions that include change in diet, exercise, and education hold significant benefit in reducing cardiovascular risk factors in patients with T2D [2].

In particular, exercise training (ET) has long been considered a cornerstone in the management of T2D [3]. Aerobic and resistance activities produce differing metabolic and molecular responses [4]. It is well established that the exercise increases skeletal muscle glucose uptake through an insulin-independent pathway [5], indicating muscle contraction directly impacts glucose homeostasis. In fact, skeletal muscle plays a primary role in glycemic control and metabolic homeostasis, being a predominant site of glucose disposal under insulin-stimulated conditions [6]. Although aerobic and resistance exercise are individually capable of promoting substantial health benefits, the signaling pathways and physiologic effects are specific to training mode [4]. Aerobic exercise improves mitochondrial biogenesis [7], the intrinsic oxidative capacity of muscle, and the delivery and utilization of substrates in working muscle $[8,9]$. Conversely, resistance exercise induces morphological and neurological adaptations which contribute to changes in muscle neural firing pattern, size (i.e., hypertrophy), and function (i.e., strength and power) $[10,11]$.

Ideally, both aerobic and resistance components are included in an individualized ET program [3]. Inclusion of both aerobic and resistance ET improves aerobic capacity/performance, muscle strength, and endurance and preserves muscle mass [12], all importantly contributing to improvements in cardiovascular risk profile, morbidity, and mortality [13].

In a well-designed study with a statistically robust sample size, Sigal et al. observed that combined aerobic and resistance training over a long period was superior to either mode in isolation in improving glycemic control [14]. However, in this study, although there was a progression of training intensity, combined training was only individually applied during the first 4 weeks, and the type, order, and progression of resistance exercises prescribed were not clear and were not well described. Church et al. observed that a combined exercise training program was more effective in improving HbA1c [15]. Although the authors clearly describe the intensity of aerobic and resistance training as well as the types of resistance exercises, the daily sequence of training as well as progression was unclear. Such details are very important when considering the optimization of results, especially for short-duration training programs.

In 1980, Hickson was the first to investigate the effects of a concurrent exercise training program, which combined aerobic and resistance components during the same session [16]. Recently, programs that combine aerobic and resistance training have been investigated with a focus on optimizing outcomes, i.e., the magnitude of physiologic and clinical improvements. Recent evidence indicates concurrent ET leads to less than optimal improvements in muscle strength [17]. In addition, other studies have found concurrent ET leads to less than optimal improvements in peak oxygen uptake $\left(\mathrm{VO}_{2}\right)$ in healthy males [18].

To our knowledge, it is unclear whether concurrent training can enhance or impair parameters of strength and aerobic capacity in patients with T2D. In addition, it is unclear if a concurrent ET training program implemented for a short period could produce positive adaptations, while considering aspects such as an individualized training approach during supervised sessions, taking into account the order of application. As such, addressing these issues is the primary objective of the current investigation. We hypothesize that a welldesigned, short duration, concurrent ET program can lead to a reduction in HbA1c as well as improvements in peak $\mathrm{VO}_{2}$, peripheral muscle strength, and cardiovascular risk profile in a T2D cohort.

\section{Methods}

\section{Design, Recruitment Process, and Population}

Participants were recruited through word of mouth, radio advertisements, local e-mail subscription services, social media, and flyers. All potential participants were screened for exclusion criteria via telephone scripts and face-to-face interviews.

The current investigation recruited and enrolled a total of 41 patients ( 15 females and 19 males) with a confirmed diagnosis of T2D, aged $51 \pm 7$ years. Duration of T2D was based on a self-reported date of diagnosis. 
The experimental procedures were performed in the Cardiopulmonary Physiotherapy Laboratory at the Federal University of São Carlos, and blood collection was performed at the Clinical Analysis Laboratory in the same location.

Eligibility criteria were (1) established diagnosis of T2D confirmed by a physician and (2) a sedentary lifestyle for at least 6 months according to the American Heart Association criteria [19]. Exclusion criteria consisted of (1) a confirmed diagnosis of any heart disease, (2) uncontrolled hypertension, (3) any musculoskeletal disorders, (4) any confirmed diagnosis of respiratory disease, and (5) confirmed autonomic neuropathy. Autonomic neuropathy was considered when the patient presented with a clinical diagnosis and/or heart rate $>100 \mathrm{bpm}$ [20] and a validated symptomatology 7 question tool [21]. The study followed the Declaration of Helsinki guidelines and was approved by the Human Research Ethics Committee of our Institution (protocol number 1318/1). The procedure was explained and subjects subsequently confirmed their participation in the study by written informed consent. Written informed consent was obtained from the patient for publication of this original manuscript and any accompanying images.

\section{Randomization}

The current study is a randomized controlled trial (RCT) (RBR 492q8z) available from http://www.ensaiosclinicos.gov.br/rg/?q=RBR-492q8z. Allocation was performed by a person not involved in the study selecting the envelope from a box. Participants included in the study were randomized by 41 sealed opaque envelopes, 21 to the concurrent ET group (CART-G) and 20 to the sedentary group (SG). Subjects were randomized in an equal ratio (1:1) with a random block size of 4 .

The data were analyzed by a specialist who was blinded to participant group allocation.

\section{Outcomes}

Primary outcome: The primary outcome measures were change in $\mathrm{HbA1c}$, peal $\mathrm{VO}_{2}$, and biochemical analyses in T2D patients after a 12-week concurrent ET program.

Secondary outcome: As a secondary outcome measure, we analyzed changes in peripheral muscle strength and body composition following a 12-week concurrent ET program.

\section{Procedures and Data Collection}

All subjects were evaluated during the same time of the day (in order to consider differences in response due to circadian rhythm) in an experimental room with a temperature of $22{ }^{\circ} \mathrm{C}$ and relative air humidity between 50 and $60 \%$.

\section{Skinfold Thickness}

Skinfolds of the biceps, triceps, subscapular, suprailiac, abdomen, and thigh were measured thrice using metal calipers (Cescorf, Porto Alegre, Rio Grande do Sul, Brazil). The average of the three skinfold measurements was used for calculation of percent body fat [22].

\section{Body Circumferences}

The circumference of the arm, axillary, xiphoid, hip, waist, and thigh was measured using a flexible tape measure with $0.1-\mathrm{cm}$ increments. Waist circumference was measured at the level of the umbilicus and the hips at the level of the iliac crest taken with the patient in a standing position. All measurements were performed thrice by a researcher who had been previously trained and certified to perform these procedures; the average of the three measurements was used for calculation [22].

Body composition was assessed by bioelectrical impedance analysis using the Tanita Bc533 and previously described methodology [23, 24].

\section{Biochemical Measurements}

Blood specimens were obtained after an overnight fast for all measurements. HbAlc was measured in a central laboratory by anion exchange high-performance liquid chromatography (Variant II, BioRad, Berkeley, CA), coupled with a fluorescence detector method certified by the National Glycohemoglobin Standardization Program [25]. Fasting plasma glucose was measured by an enzymatic method using an AU $680^{\circ}$ (Beckman Couter, Suarlée (NAMUR) Belgium), and fasting plasma insulin was measured by a chemiluminescent assay (UniCel ${ }^{\circ}$ DxI 800, Pasadena, CA). Total cholesterol (total-C), lowdensity lipoprotein cholesterol (LDL-C), high-density lipoprotein cholesterol (HDL-C), and triglycerides were measured by an enzymatic method AU 680 (Beckman Couter, Suarlée (NAMUR) Belgium) [26].

\section{Cardiopulmonary Exercise Testing (CPX)}

A symptom-limited incremental exercise test was performed on a cycle ergometer (Recumbent Corival of MedGraphics, MN, USA) with the collection of gas exchange and ventilatory variables using a calibrated computer-based exercise system (Metabolic analyzer System Greenhouse telemetry module for field studies Oxycon-Mobile, Jaeger, Hoechberg, Germany).

The day before CPX, the subjects were taken to the experimental room for familiarization with the procedures and equipment to be used. All subjects were instructed to (1) avoid caffeinated and alcoholic beverages or any other stimulants the night before and the day of data collection, (2) not to perform activities requiring moderate-to-heavy physical exertion on the day 
before data collection, and (3) not to speak unnecessarily during the evaluation to avoid HR signal interference.

The exercise test consisted of (1) 5 min of rest, (2) 4 min with real "zero" workload, obtained by means of a system which moves the ergometer freewheel at 60 revolutions per minute (rpm), (3) the incremental phase, (4) 1 min active recovery period, and (5) 5 min passive recovery period. The workload (W) was continuously increased in a linear "ramp" pattern of $15 \mathrm{~W} \mathrm{~min}{ }^{-1}$ [27], so that the incremental exercise testing duration was between 8 and $12 \mathrm{~min}$ [28]. The test finished when subjects reached physical exhaustion or demonstrated abnormal test responses that warranted test termination [27].

Peak $\mathrm{VO}_{2}$ was defined as the highest 15-s average value during the test [29]. Fifteen-second averaged ventilation $\left(\mathrm{V}_{\mathrm{E}}\right)$ and carbon dioxide production $\left(\mathrm{VCO}_{2}\right)$ data, obtained from the initiation of exercise to peak, were inputted into a spreadsheet software (Microsoft Excel, Microsoft Corp., Bellevue, WA, USA). $\mathrm{V}_{\mathrm{E}}$ and $\mathrm{VCO}_{2}$ responses throughout exercise were used to calculate the $\mathrm{V}_{\mathrm{E}} / \mathrm{VCO}_{2}$ slope via least squares linear regression $(y=$ $\mathrm{mx}+\mathrm{b}, m=$ slope) [30].

\section{Isokinetic Strength Test}

Isokinetic concentric knee-extensor strength on the dominant side was performed at a speed of $60 \%$ s using an isokinetic dynamometer (Biodex Medical Systems 3, Shirley, NY). Positioning and stabilization of the subjects was standardized. Mechanical axis of rotation of the level arm was aligned to the axis of rotation of the joint being tested. The resistance pad at the end of the level arm was strapped to the most distal part of the tibia. Correction for the effect of gravity was made. After stretching, a warm-up exercise was performed on the dynamometer. The order of peripheral muscle tests applied was as follows: (1) Protocol 1, which was for the analysis of the maximal isokinetic strength, the volunteers performed five maximal efforts to determine maximal peak torque (in $\mathrm{N} \mathrm{m}$ ) at low angular velocity (U) of $60^{\circ} / \mathrm{s}$; (2) Protocol 2, which was for the analysis of isokinetic endurance, the participants performed efforts for $1 \mathrm{~min}$ at a high angular velocity of $300 \% \mathrm{~s}$ to determine average power (in W). This protocol assessed muscular efficiency and total work (in J) [31].

\section{One-Repetition Maximum Test (1-RM)}

To determine protocol loads, the 1-RM test was applied by gradually increasing resistance until the volunteer succeeded in performing no more than one repetition [32]. The 1-RM test was performed for all eight exercises.

\section{Concurrent Aerobic and Resistance Training Program (CART)}

The training protocol for the CART-G consisted of individually supervised sessions on alternate days, $\sim 210 \mathrm{~min} /$ week, three times per week, for 12 weeks, totaling 36 sessions.

All training sessions were carried out under the individual supervision of exercise specialists. Each session lasted $\sim 1 \mathrm{~h}$ and $10 \mathrm{~min}$ and included a (1) 5-min warm-up, (2) 60-min CART training, and (3) 5-min cool down. The protocol was performed for three separate sessions before determination of the 1-RM to allow familiarization of equipment. In order to avoid a bias effect during the training program, during each exercise session day, the subjects alternated the order of training (i.e., aerobic training first followed by resistance training and subsequently resistance training followed by aerobic training). Resistance training was performed at $60-80 \%$ of predicted 1RM [33] and consisted of eight resistance exercises targeting all major muscle groups as recommended by the American Diabetes Association [34]. Subjects performed sets of four upper body exercises (biceps free weights; seated row; triceps and, flat bench press) and three sets of four lower body exercises (leg press; leg extension; calf and, seated leg curl). Each maneuver consisted of three sets of 10-12 repetitions. The amount of weight lifted was progressively increased through sessions in order to maintain consistent repetitions during the training program. The participants were advised to rest 2 to 3 min between sets to allow for maximal muscle recovery.

Aerobic training was performed at the HR corresponding at $60-70 \%$ of peak $\mathrm{VO}_{2}$ assessed by CPX. Each training session was $30 \mathrm{~min}$ in duration [34].

The workload during both aerobic and resistance training was gradually increased after experimental measures. Skinfold thickness, body circumferences, biochemical measurements, CPX isokinetic strength test, and the 1RM test were assessed at the midway point of the protocol (i.e., sixth week). Table 1 lists the CART progression.

Heart rate, blood pressure, and blood glucose measurements were monitored pre and post exercise sessions, in order to identify any adverse events. If blood glucose was $>13.9 \mathrm{mmol} / \mathrm{l}(250 \mathrm{mg} / \mathrm{dl})$ prior to exercise, the session was canceled. If blood glucose was $>13.9 \mathrm{mmol} / \mathrm{l}$ more than two times in a same week, the subject was referred for a physician visit. All the subjects completed 36 sessions. Following the 12week CART protocol, the subjects were re-evaluated.

All participants were instructed to maintain their usual medical care and they received dietary advice on healthy eating [35], but there was no specific dietary intervention with regard to eating habits. Subjects were given the opportunity to miss or cancel sessions with a makeup session scheduled as soon as possible. 
Table 1 Pearson correlation between HbA1c post X skinfold post in the CART group

\begin{tabular}{|c|c|c|c|c|}
\hline \multirow[b]{2}{*}{ Weeks } & \multicolumn{2}{|l|}{ Aerobic } & \multicolumn{2}{|l|}{ Resistance } \\
\hline & Intensity $\left(\mathrm{VO}_{2}\right)(\%)$ & Duration (min) & Intensity & Sets/repetitions \\
\hline 1 & 60 & 30 & $60 \% 1-\mathrm{RM}$ & $3 / 10$ \\
\hline 2 & 60 & 30 & $60 \% 1-R M$ & $3 / 10$ \\
\hline 3 & 65 & 30 & $70 \% 1-\mathrm{RM}$ & $3 / 10-12$ \\
\hline 4 & 65 & 30 & $70 \% 1-R M$ & 3/10-12 \\
\hline 5 & 70 & 30 & $75 \% 1-\mathrm{RM}$ & $3 / 10-12$ \\
\hline 6 & 70 & 30 & $75 \% 1-R M$ & $3 / 12$ \\
\hline 7 & 70 & 30 & $75 \% 1-\mathrm{RM}$ & $3 / 12$ \\
\hline 8 & 70 & 30 & $75 \% 1-R M$ & $3 / 12$ \\
\hline 9 & 80 & 30 & $80 \% 1-R M$ & $3 / 10$ \\
\hline 10 & 80 & 30 & $80 \% 1-R M$ & $3 / 10-12$ \\
\hline 11 & 80 & 30 & $80 \% 1-\mathrm{RM}$ & $3 / 10-12$ \\
\hline 12 & 80 & 30 & $80 \% 1-R M$ & $3 / 12$ \\
\hline
\end{tabular}

In this context, the duration of the program did not exceed 12 weeks.

\section{Statistical Analysis}

Sample size calculation, based on a previous study [15], suggested that recruitment of 12 patients in each group would provide sufficient statistical power for the primary endpoint (i.e., peak $\mathrm{VO}_{2}$ ). The power $(80 \%)$ at an $\alpha$ level of 0.05 to detect a significant difference in peak $\mathrm{VO}_{2}\left(\mathrm{ml} \mathrm{kg}^{-1} \mathrm{~min}^{-1}\right)$ of $\sim 1.2 \mathrm{ml} \mathrm{kg}{ }^{-1} \min ^{-1}$ between groups was used.

The sample size was determined a priori through GPower software 3.1.9. Considering the main outcome was the mean difference between groups and times (analysis of variance (ANOVA): repeated measures, within-between interaction, effect size $=0.40$, with $\alpha=0.05, \beta=80 \%, d=$ 0.8 ) and the allocation ratio was $1: 1$, the calculated sample size was 16 for each group. Anticipating a dropout rate, more subjects were recruited in each group.

Data are presented as mean and standard deviation after testing for normal distribution by the Shapiro-Wilk test. Differences between the two groups (SG versus CART-G data) were assessed by unpaired Student's $t$ test.

Significance of between-group differences in medication changes was evaluated by Fisher's exact test for categorical variables.

The effect of time (pre compared with post 3 months, p, i.e., effect of CART), group (SG compared with CART-G), and interaction between time and group effects were evaluated by two-way ANOVA for repeated measures.

Pearson's correlations were tested to contrast the association between changes in variables pre and post training, followed by linear regression. All other data analysis was performed using the STATISTICA 5.5 software package $\left(\right.$ Stat $\left.\mathrm{Soft}^{\oplus}\right)$ and SigmaPlot ${ }^{\oplus} 11$. The level of significance was set at $P \leq 0.05$ for all statistical tests.

The magnitude of the correlations was determined considering the following classification scheme for $r$ values: $\leq 0.35$ low or weak, $0.36 \leq 0.67$ moderate, $\geq 0.68$ strong or high, $\geq 0.9$ very high, and 1 perfect [36]. The probability of a type I error was established at $5 \%$ for all tests $(\alpha=0.05)$.

Subjects included in the final analysis had at least $80 \%$ adherence to their exercise prescription over the 12week protocol; there was $100 \%$ adherence in CART-G

\section{Results}

Sixty participants were screened; before the randomization, 12 more were excluded, 4 not meeting inclusion criteria, 4 declining to participate, and 4 living too far of a distance for data collection. Forty-eight subjects underwent randomization. Post-randomization but prior to training, two additional participants were excluded in the CART-G, one due to gynecologic surgery and the other voluntarily withdrew during the first week of training. Five withdrew from the SG post-randomization, one for personal reasons, one started to use insulin, and three moved to another city. All remaining 41 volunteers successfully completed the study, 20 in the control and 21 in the CART-G. No adverse events were identified during the protocol application. The randomization flow chart is illustrated in Fig. 1.

As summarized in Table 2, there were no statistically significant differences in anthropometric and demographic characteristics, risk factors and/or medications between the two groups at baseline, demonstrating successful randomization.

A two-way ANOVA was conducted to examine the effect of time (effect of pre and post 3 months) and group (SG vs. CART-G) on metabolic profile, glycemic control, peripheral muscular strength, and exercise capacity status. In Table 3 , in relation to body composition, there were no differences in weight and BMI post exercise. However, visceral fat decreased significantly in the CART-G only $(10.9 \pm 4.1$ to $9.7 \pm 4.2-11 \%)$.

Also, HbA1c decreased by $9.9 \%(65.4 \pm 17.9$ to $55.9 \pm$ $12.7 \mathrm{mmol} / \mathrm{mol}$ ) in the CART-G compared to baseline. Comparing the post-intervention difference between the SG and CART-G, the difference in HbA1c reached $17.1 \%(72.5 \pm 20.9$ to $55.9 \pm 12.7 \mathrm{mmol} / \mathrm{mol})$. Moreover, LDL/HDL decreased in the CART-G $(P<0.05)$ while LDL/HDL and total cholesterol increased in the SG.

There was only a difference in resting systolic blood pressure (SBP) (129.7 to $118 \mathrm{mmHg}$ ) after CART-G, with no change in diastolic blood pressure (DBP).

All skinfolds decreased post exercise according to time and group [(i.e., interaction time (effect of exercise) vs. 


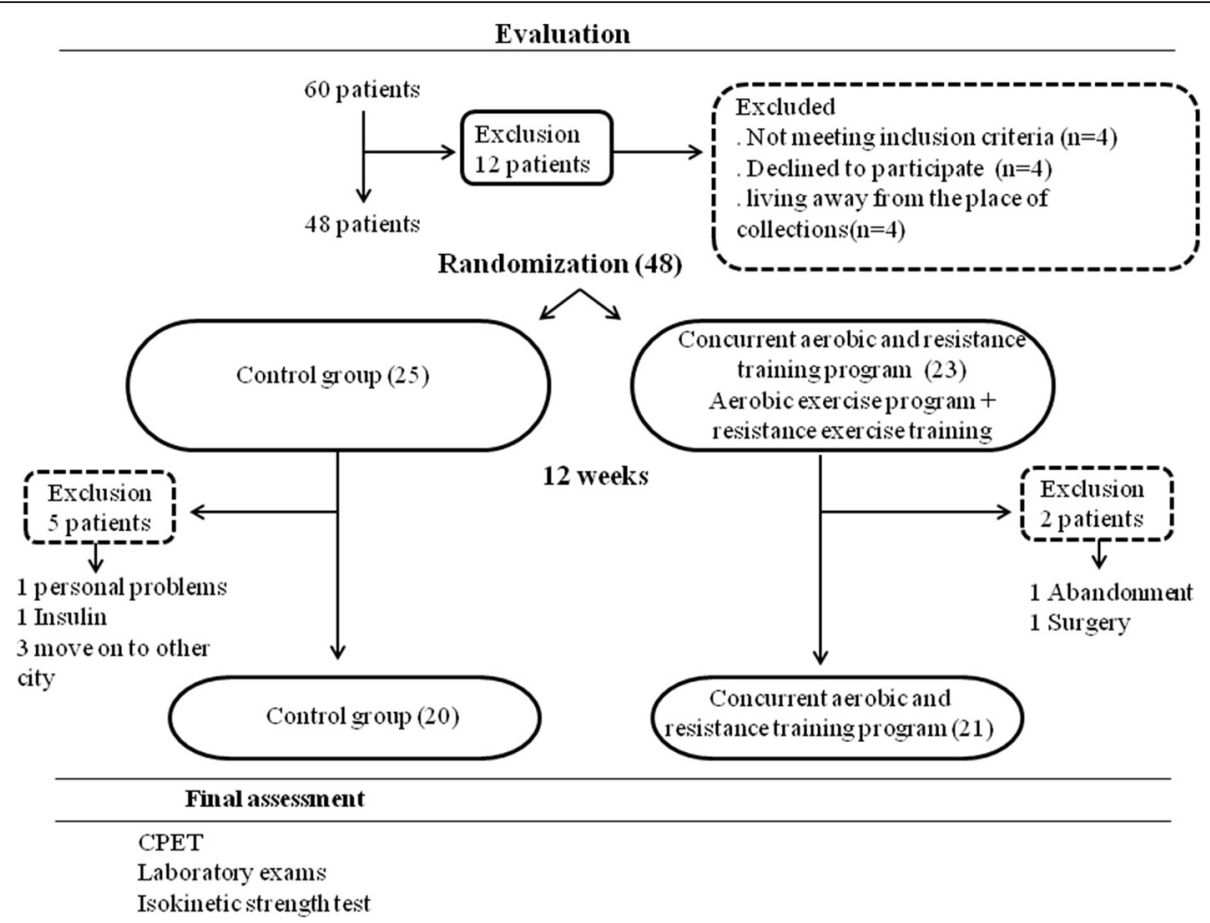

Fig. 1 Flowchart with randomization study

group (SG vs. CART-G), $(p<0.05)]$. However, arm, umbilicus, hip, and thigh circumferences did not decrease after 3 months of exercise.

After 3 months, CART-G increased relative and absolute peak $\mathrm{VO}_{2}$ by $18.7 \%$ [ $22.9 \pm 6.1$ to $27.2 \pm 4.7 \mathrm{ml} \mathrm{kg}$ $\left.{ }^{-1} \min ^{-1}(p=0.002)\right]$ as well as peak workload $(p \leq 0.001)$, $\mathrm{V}_{\mathrm{E}}(p \leq 0.001), \mathrm{VCO}_{2}(p=0.004)$, and the $\mathrm{VE} / \mathrm{VCO}_{2}$ slope $(p=0.006)$. These statistical differences, according to time and group [(i.e., interaction time (effect pre and post) vs. group (SG vs. CART-G)], describe the simultaneous positive influence of a supervised, individualized CART program on $\mathrm{VO}_{2}$ (Table 4).

Finally, the CART-G demonstrated a significant improvement in peripheral muscle strength; peak torque to body weight ratio extensors by $17.2 \%(167 \pm 41.5$ to 195.8 $\pm 43.6 \%$ ), peak torque to body weight ratio flexors by $32 \%(87.9 \pm 14.7$ to $116 \pm 30.1 \%)$, and total work flexion increase by $26 \%(1340.3 \pm 453.8$ to $1685 \pm 717.1 \mathrm{~J})$ (Table 5). Interestingly, the difference between groups in muscular strength, after 3 months, was observed only in the flexor muscles, also evidenced by peak torque to body weight ratio ( $\mathrm{SG}=89.5 \pm 19.1 \%$ vs. CART-G $=116 \pm$ $30.1 \%)$. The 1-RM test increased for all equipment when compared pre and post CART-G (Table 6).

Peak $\mathrm{VO}_{2}$ was correlated negatively with $\mathrm{HbA1c}$ (Fig. 2). Correlations between triceps, biceps, subscapular, suprailiac and, abdominal skinfolds, and HbA1c were low to moderate (Table 7). No significant correlations were found between parameters of body composition, strength and insulin resistance.

\section{Discussion}

Several aspects making this an innovative investigation (1) demonstrated that a 12-week supervised, individualized, and personalized CART significantly improved (1) glycemic control, (2) body composition, (3) peak $\mathrm{VO}_{2}$, and (4) muscular strength. Additionally, peak $\mathrm{VO}_{2}$ was correlated with HbA1c. This is the first study, to our knowledge, that assessed CART using an individualized, supervised approach over a 12-week period. Furthermore, there was $100 \%$ adherence to the program.

In type-1 diabetes patients with poor glycemic control, Tagougui et al. concluded that the glycation of hemoglobin itself could play a role in reducing the gain in peak $\mathrm{VO}_{2}$. Additionally, it was demonstrated that poor glycemic control during exercise blunted the deoxyhaemoglobin $(\mathrm{HHb})$ increase, indicating lower muscle oxygen extraction and a higher oxygen affinity for glycated hemoglobin [37]. Furthermore, it has been shown that increased $\mathrm{VO}_{2}$ peak is associated with decreased cardiovascular and all-cause mortality [38]. From a clinical perspective, our data indicate that CART can be an effective strategy in reducing cardiovascular risk factors with potential beneficial effects on $\mathrm{VO}_{2}$ and peripheral muscle strength in patients with T2D. 
Table 2 Anthropometric and demographic data, risk factors, and medications of the sedentary (SG) and the concurrent aerobic and resistance training groups (CART)

\begin{tabular}{|c|c|c|c|}
\hline Variables & SG $(N=20)$ & CART-G $(N=21)$ & $P$ \\
\hline Age (years) & $52.1 \pm 7.3$ & $49.5 \pm 6.1$ & 0.21 \\
\hline Height (cm) & $167 \pm 0.1$ & $169 \pm 0.1$ & 0.53 \\
\hline Weight (kg) & $85 \pm 18.6$ & $82.2 \pm 19.4$ & 0.63 \\
\hline $\mathrm{BMI}\left(\mathrm{kg} / \mathrm{m}^{2}\right)$ & $30.4 \pm 5.8$ & $30.1 \pm 5.4$ & 0.28 \\
\hline Duration type 2 diabetes (years) & $7.4 \pm 5.8$ & $5.7 \pm 5.5$ & 0.17 \\
\hline SBP rest $(\mathrm{mmHg})$ & $131.1 \pm 16.5$ & $129.7 \pm 15.8$ & 0.79 \\
\hline DBP rest $(\mathrm{mmHg})$ & $89.4 \pm 8.0$ & $92 \pm 11.1$ & 0.40 \\
\hline $\mathrm{HR}(\mathrm{bpm})$ & $83 \pm 12.5$ & $85.5 \pm 13.1$ & 0.54 \\
\hline \multicolumn{4}{|l|}{ Risk factors \% (n) } \\
\hline Tabagism & 0 & 0 & - \\
\hline CAD family history & $20(4)$ & $23.8(5)$ & 1.00 \\
\hline Dyslipidemia & $50(10)$ & $42.8(9)$ & 0.75 \\
\hline Obesity & $55(11)$ & $38(8)$ & 0.35 \\
\hline $\mathrm{SAH}$ & $60(12)$ & $47.6(10)$ & 0.53 \\
\hline \multicolumn{4}{|l|}{ Medications } \\
\hline \multicolumn{4}{|l|}{ Hypoglycemiants \% (n) } \\
\hline Biguanides & $95(19)$ & $85.7(18)$ & 0.60 \\
\hline Sulfonylurea & $45(9)$ & $47.6(10)$ & 1.00 \\
\hline \multicolumn{4}{|l|}{ Antihypertensive } \\
\hline ACE I inhibitors & $15(3)$ & $14.3(3)$ & 1.00 \\
\hline Renin inhibitors & & & 1.00 \\
\hline ARAll & $25(5)$ & $20(4)$ & 0.71 \\
\hline Diuretics & $5(1)$ & $9.5(2)$ & 0.60 \\
\hline \multicolumn{4}{|l|}{ Hypolipemiant } \\
\hline Estatins & $15(3)$ & $19(4)$ & 1.00 \\
\hline Fibrates & $10(2)$ & - & 0.23 \\
\hline
\end{tabular}

Data are reported as means \pm SD. BMI body mass index, SBP systolic blood pressure, $D B P$ diastolic blood pressure, $H R$ heart rate, $C A D$ cardiovascular disease, $S A H$ systemic arterial hypertension, $A C E$ I angiotensin converting enzyme I inhibitor, ARAll angiotensin II receptor antagonists

\section{Effect of CART on Body Composition}

The findings of the current study demonstrated that body weight and BMI remained stable in both groups. This is consistent with several previous studies [39-41], demonstrating no difference in the body habitus characteristics post ET with a longer training duration (912 months) than the present study. However, Church et al. studied the benefits of aerobic training, resistance training, and a combination of both on HbAlc in individuals with T2D and found that the combined training group had a decrease in mean weight compared to the control and resistance training group [15]. Recently, however, Johannsen et al. found that a resistance training program for 9 months decreased body weight more than aerobic exercise; the authors attributed this finding to the increase in free fatty acids [42]. From the literature in comparison to the current study, we observed that previously reported training duration assessed was typically longer although a significant change in body weight was not common.

Body weight collectively includes not only body fat but also muscle, bone, and water. From this perspective, skinfold thickness measures may be a more sensitive and direct measure of cardiovascular risk profile (i.e., more accurately identifying adiposity profile). Moreover, changes in adiposity or total body fat are more relevant regarding risk reduction compared to quantification of body weight reduction alone [43]. In the present study, despite the fact that body weight did not change, we observed that all skinfold measurements decreased and muscular strength improved, with these data collectively speculating that CART might reduce adiposity and increase lean body mass, which are considered to be highly favorable adaptations in patients with T2D.

In this way, Boule et al. performed a meta-analysis that systematically reviewed and quantified the effect of exercise on HbA1c and body mass in T2D, concluding that exercise programs longer than 8 weeks reduce $\mathrm{HbA1c}$, although there appears to be no change in body mass [44].

\section{Effect of CART on Glycemic Control}

Surprisingly, at baseline, all study subjects had a poor glycemic control, as demonstrated by HbA1c, which remains the gold standard for assessing glucose homeostasis as an integration of both fasting and postprandial glucose variations over a 3-month period [45]. Although all subjects were diagnosed with T2D, they are under use of hypoglycemiants, some using more than one. Thus, we expected that this cohort presented with better glycemic control. In addition, all the participants were under the routine care of an endocrinologist and seen on a monthly basis for medical management.

Although few studies has found an improvement in HbA1c after a combined ET program, the subjects enrolled were prescribed insulin and utilized pneumatic machines [46] or elastic bands [47] or the time of the intervention was longer $[14,15]$. Thus, the protocol used in the current study, and therefore the results, may not be generalizable to these previous protocols. In addition, Church et al. and Sigal et al. found that a long period of combined ET program could beneficially modulate HbA1c. However, our study seems to be the first to find an important reduction in HbAlc using short-term CART, which has implications for program costs needed for implementation $[14,15]$.

Each $1 \%$ increment of HbA1c corresponds to a $29 \mathrm{mg} / \mathrm{dl}$ increase in mean glucose concentration [48]. Conversely, an absolute decrease of $1 \%$ in HbA1c levels 
Table 3 Summary of results pre and post 3 months

\begin{tabular}{|c|c|c|c|c|c|c|c|}
\hline \multirow[b]{2}{*}{ Variables } & \multicolumn{2}{|l|}{$S G(N=20)$} & \multicolumn{2}{|c|}{ CARTG $(N=21)$} & \multirow[t]{2}{*}{ Time factor } & \multirow[t]{2}{*}{ Exercise factor } & \multirow[t]{2}{*}{ Interaction } \\
\hline & Pre & Post & Pre & Post & & & \\
\hline Weight (kg) & $85.0 \pm 18.6$ & $84.1 \pm 17.9$ & $82.2 \pm 19.4$ & $81.5 \pm 19.5$ & 0.64 & 0.06 & 0.80 \\
\hline $\mathrm{BMI}\left(\mathrm{kg} / \mathrm{m}^{2}\right)$ & $30.4 \pm 5.8$ & $30.1 \pm 5.4$ & $28.6 \pm 5.2$ & $28.3 \pm 5.3$ & 0.29 & 0.06 & 0.80 \\
\hline VF (\%) & $12.5 \pm 5$ & $12.7 \pm 4.8$ & $10.9 \pm 4.1$ & $9.7 \pm 4.2 \neq \dagger$ & 0.10 & 0.16 & 0.04 \\
\hline $\mathrm{HbA1c}(\mathrm{mmol} / \mathrm{mol})$ & $71.7 \pm 18.9$ & $72.5 \pm 20.9$ & $65.4 \pm 17.9$ & $55.9 \pm 12.7 \neq \dagger$ & 0.04 & 0.08 & 0.03 \\
\hline HOMA-IR & $5.6 \pm 4.7$ & $5.2 \pm 4.4$ & $6.4 \pm 6.8$ & $5.0 \pm 4.4$ & 0.84 & 0.05 & 0.31 \\
\hline Cholesterol (mg/dl) & $196.3 \pm 44.2$ & $216.9 \pm 47.9^{*}$ & $198.3 \pm 50.3$ & $186.8 \pm 35.1$ & 0.33 & 0.35 & 0.002 \\
\hline LDL/HDL (mg/dl) & $2.6 \pm 0.9$ & $3.0 \pm 1.1^{*}$ & $2.5 \pm 0.5$ & $2.4 \pm 0.6 \dagger$ & 0.2 & 0.2 & 0.03 \\
\hline SBP rest $(\mathrm{mmHg})$ & $127 \pm 16.9$ & $131.7 \pm 24.6$ & $129.7 \pm 16.3$ & $118 \pm 12 \neq \dagger$ & 0.24 & 0.34 & 0.02 \\
\hline DBP rest $(\mathrm{mmHg})$ & $89.3 \pm 7.3$ & $859 \pm 13.8$ & $92.1 \pm 10.5$ & $81.8 \pm 6$ & 0.82 & $<0.001$ & 0.06 \\
\hline \multicolumn{8}{|c|}{ Skinfold thickness $(\mathrm{cm})$} \\
\hline Triciptal & $2.3 \pm 1$ & $2.1 \pm 0.7$ & $2.2 \pm 0.6$ & $1.6 \pm 0.5 \neq \dagger$ & 0.16 & $<0.001$ & $<0.001$ \\
\hline Biciptal & $1.4 \pm 0.8$ & $1.3 \pm 0.6$ & $1.3 \pm 0.4$ & $0.7 \pm 0.3 \neq \dagger$ & 0.06 & $<0.001$ & $<0.001$ \\
\hline Subscapular & $3.4 \pm 1.1$ & $3.6 \pm 0.9$ & $3.2 \pm 0.9$ & $2.4 \pm 0.9 \neq \dagger$ & 0.02 & $<0.001$ & $<0.001$ \\
\hline Suprailiac & $3.2 \pm 1.3$ & $3.5 \pm 1.5$ & $3.3 \pm 1.1$ & $2.2 \pm 0.9 \neq \dagger$ & 0.11 & 0.003 & $<0.001$ \\
\hline Abdominal & $4.8 \pm 1.8$ & $4.7 \pm 1.8$ & $4.3 \pm 1.6$ & $3.1 \pm 1.1 \neq \dagger$ & $<0.001$ & $<0.001$ & $<0.001$ \\
\hline Thigh & $2.8 \pm 1.0$ & $2.7 \pm 0.9$ & $3.0 \pm 1.4$ & $1.7 \pm 0.8 \neq \dagger$ & 0.34 & $<0.001$ & $<0.001$ \\
\hline \multicolumn{8}{|l|}{ Cirtometry (cm) } \\
\hline Arm & $34.4 \pm 4.2$ & $36.1 \pm 7.8$ & $33.8 \pm 3.7$ & $33.3 \pm 3.8$ & 0.25 & 0.44 & 0.13 \\
\hline Axillary & $108 \pm 11.5$ & $106.7 \pm 11.6$ & $105.9 \pm 11.3$ & $101.2 \pm 13+$ & 0.30 & 0.002 & 0.06 \\
\hline Xiphoid & $102.2 \pm 12.6$ & $101.6 \pm 12.5$ & $99 \pm 12.3$ & $96.7 \pm 12.5 \neq \dagger$ & 0.31 & $<0.001$ & 0.02 \\
\hline Waist & $100.8 \pm 13.5$ & $100.4 \pm 13.3$ & $95.3 \pm 13$ & $91.5 \pm 13.6 \neq \dagger$ & 0.09 & $<0.001$ & $<0.001$ \\
\hline Umbilicus & $105.2 \pm 12.5$ & $104.6 \pm 12.1$ & $98 \pm 16.4$ & $95 \pm 11.9$ & 0.04 & 0.15 & 0.32 \\
\hline Hip & $104.2 \pm 11.2$ & $103.3 \pm 8.6$ & $102.9 \pm 9.8$ & $99 \pm 8.7$ & 0.33 & 0.02 & 0.17 \\
\hline Thigh & $57.4 \pm 5.4$ & $56.7 \pm 5.7$ & $55.8 \pm 7.5$ & $56.7 \pm 6.1$ & 0.70 & 0.91 & 0.22 \\
\hline
\end{tabular}

Data are reported as means \pm SD. BMI body mass index, HOMA-IR homeostatic model assessment insulin resistance, LDL/HDL low-density lipoproteins/high-density lipoproteins, $S B P$ systolic blood pressure, $D B P$ diastolic blood pressure, $\mathrm{mmHg}$ millimeter of mercury. $P \leq 0.05$, *sedentary group pre $\times$ sedentary group post; $\neq$ exercise group pre $\times$ exercise group post, + sedentary group post $\times$ exercise group post

has been associated with a 15 to $20 \%$ decrease in cardiovascular events [49]. To our knowledge, this current study is the first randomized trial to demonstrate as profound a decrease in HbA1c (9.9 \%) when compared to baseline using a CART protocol and a $17.1 \%$ when comparing the CART-G to the SG following the trial.

More in line with the present study, Church et al. after 9 months of aerobic and resistance training, when compared to a non-exercise control group, showed a reduction in HbA1c levels [15]. Sigal et al. demonstrated the same benefits, but after 22 weeks, where HbA1c decreased by approximately $13 \%$. In the present study, considering the specificity of our CART program, we demonstrated the same benefits in a shorter time frame [14]. The established HbA1c goal by an International Expert Committee [50] is $6.5 \%$ or $47.5 \mathrm{mmol} / \mathrm{mol}$. As such, CART may prove to be a valuable intervention strategy to achieve this goal. Even so, in many patients with T2D, with all the efforts and intensive treatment, optimal glycemic control may be difficult to achieve $[51,52]$.

Effect of CART on Cardiorespiratory and Metabolic Profile Awotidebe et al. previously demonstrated that patients with T2D demonstrated a lower peak $\mathrm{VO}_{2}$ compared with healthy controls [53]. Our findings show that exercise training was associated with significant increase in $\mathrm{VO}_{2}$ peak, which was also correlated to the decrease in HbA1c. These findings collectively indicate that in addition to a significant improvement in aerobic capacity with ET [54], there is increased insulin action [55] and improved blood glucose levels [14], which could be due to upregulation of GLUT-4 transporter expression at a cellular level. This mechanistic pathway is of great clinical importance, indicating the particular benefit of a concurrent ET program in patients with T2D.

Similar results were demonstrated by Larose et al. in the DARE trial, where T2D patients were randomly 
Table 4 Cardiopulmonary exercise testing responses pre and post 3 months

\begin{tabular}{|c|c|c|c|c|c|c|c|}
\hline \multirow{2}{*}{$\begin{array}{l}\text { Variables } \\
\text { CPX (peak) }\end{array}$} & \multicolumn{2}{|l|}{$S G(N=20)$} & \multicolumn{2}{|l|}{ CART-G $(N=21)$} & \multirow[t]{2}{*}{ Time factor } & \multirow[t]{2}{*}{ Exercise factor } & \multirow[t]{2}{*}{ Interaction } \\
\hline & Pre & Post & Pre & Post & & & \\
\hline Workload (watts) & $123.6 \pm 36.9$ & $122.1 \pm 32.9$ & $124.6 \pm 29.1$ & $149.9 \pm 29 \neq \dagger$ & 0.19 & $<0.001$ & $<0.001$ \\
\hline$V_{E}\left(\mid \min ^{-1}\right)$ & $74.2 \pm 21.2$ & $62.8 \pm 14.0$ & $72.4 \pm 15.2$ & $80.6 \pm 13.7 \neq \dagger$ & 0.12 & 0.53 & $<0.001$ \\
\hline $\mathrm{VO}_{2}\left(\mathrm{ml} \mathrm{kg}^{-1} \mathrm{~min}^{-1}\right)$ & $21.7 \pm 4.5$ & $21 \pm 3.3$ & $22.9 \pm 6.1$ & $27.2 \pm 4.7 \neq \dagger$ & 0.02 & 0.02 & 0.002 \\
\hline $\mathrm{VO}_{2}\left(\mathrm{ml} \mathrm{min}{ }^{-1}\right)$ & $1935.7 \pm 581.1$ & $1796.9 \pm 485.4$ & $2074 \pm 443.8$ & $2323.3 \pm 523.8 \neq \dagger$ & 0.38 & 0.05 & 0.004 \\
\hline $\mathrm{VO}_{2}\left(\mathrm{ml} \mathrm{min}{ }^{-1}\right) \%$ pred & $108.8 \pm 21.3$ & $102.3 \pm 20.5$ & $111.8 \pm 24.6$ & $125.5 \pm 27 \neq \dagger$ & 0.28 & 0.09 & 0.004 \\
\hline $\mathrm{VCO}_{2}\left(\mathrm{ml} \mathrm{min}^{-1}\right)$ & $2240.2 \pm 612.6$ & $2068.5 \pm 444.1$ & $2269.1 \pm 478.7$ & $2542.8 \pm 485.5 \neq \dagger$ & 0.14 & 0.48 & 0.004 \\
\hline$V_{E} N_{C O}$ slope & $32.6 \pm 3.6$ & $30.1 \pm 3.1$ & $31.6 \pm 3.6$ & $32.4 \pm 3.1$ & 0.55 & 0.17 & 0.006 \\
\hline RER & $1.3 \pm 0.1$ & $1.2 \pm 0.1$ & $1.2 \pm 0.1$ & $1.2 \pm 0.1$ & 0.40 & 0.03 & 0.72 \\
\hline $\mathrm{HR}(\mathrm{bpm})$ & $147.6 \pm 13.9$ & $139.9 \pm 19.3$ & $146.7 \pm 12.9$ & $149.8 \pm 14.4$ & 0.33 & 0.34 & 0.03 \\
\hline HR (bpm) \% pred & $91 \pm 10$ & $86 \pm 15$ & $84 \pm 22$ & $90 \pm 11$ & 0.36 & 0.95 & 0.03 \\
\hline $\mathrm{O}_{2}$ pulse $\left(\mathrm{ml}\right.$ beat $\left.^{-1}\right)$ & $10.5 \pm 3.6$ & $10.9 \pm 3.4$ & $11.7 \pm 2.1$ & $12.8 \pm 3.1$ & 0.08 & 0.12 & 0.07 \\
\hline Dyspnea (0-10) & $5.1 \pm 2.9$ & $4.3 \pm 2.1$ & $5.4 \pm 2.4$ & $6.1 \pm 1.6$ & 0.07 & 0.86 & 0.09 \\
\hline Leg effort (0-10) & $4.7 \pm 2.9$ & $4.4 \pm 2.2$ & $5.1 \pm 2.6$ & $5.8 \pm 2.6$ & 0.19 & 0.70 & 0.32 \\
\hline
\end{tabular}

Data are reported as means \pm SD. $P \leq 0.05$, sedentary group pre $\times$ sedentary group post; łexercise group pre $\times$ exercise group post, tsedentary group post $\times$ exercise group post

allocated into aerobic, resistance, or aerobic plus resistance training groups. This study demonstrated a link between positive changes in $\mathrm{VO}_{2}$ and $\mathrm{HbAlc}$ in the combined aerobic and resistance training group only [56]. The authors speculated this combined training program uniquely resulted in favorable adaptations in glucose metabolism at the cellular level [56].

In the present study, we observed that changes in peak $\mathrm{VO}_{2}$ could predict $21 \%$ of the changes expected for HbA1c, which can explain the link between metabolic profile and exercise performance using the CART program. In parallel, Sénéchal et. al. reporting results from the HART-D study, demonstrated an association between the change in $\mathrm{VO}_{2}$ (quantified by estimated peak METs) and a reduction in central adiposity were the most prominent predictors of the change in HbA1c in response to a 9-month ET program [54].

\section{Effect of CART on Muscle and Endurance Strength}

It is already known that the skeletal muscle is responsible for approximately $75 \%$ of whole body insulinstimulated glucose uptake [57]. In the current study, after CART, the subjects showed improved muscle strength, demonstrated by peak of torque to body weight ratio (increase of $17.2 \%$ in extensor and $32 \%$ in flexor) as well as improved endurance of leg flexors (26\%). These results, associated with a reduction in thigh skinfold measurements, we speculated may indicate an increase in muscle mass, although direct measurements of lean mass gains were not explored in this study. This finding also has a high clinical relevance, particularly considering a decreased muscle mass is considered to be a major impairment among patients with T2D [58]. Our findings are also consistent with Maiorana et al., investigating the effect of a short-term 8-week circuit training

Table 5 Isokinetic strength and endurance test responses pre and post 3 months

\begin{tabular}{|c|c|c|c|c|c|c|c|}
\hline \multirow{2}{*}{$\begin{array}{l}\text { Variables } \\
\text { Isokinetic strength test }\end{array}$} & \multicolumn{2}{|l|}{$S G(N=20)$} & \multicolumn{2}{|l|}{ CARTG $(N=21)$} & \multirow[t]{2}{*}{ Time factor } & \multirow[t]{2}{*}{ Exercise factor } & \multirow[t]{2}{*}{ Interaction } \\
\hline & Pre & Post & Pre & Post & & & \\
\hline Peak torque extension ( $\mathrm{N} \mathrm{m}$ ) & $145.3 \pm 47.9$ & $143 \pm 42.2$ & $135.5 \pm 41$ & $159.7 \pm 47.7 \neq$ & 0.82 & 0.002 & $<0.001$ \\
\hline Peak torque flexion ( $\mathrm{N} \mathrm{m}$ ) & $74.8 \pm 26.4$ & $72.2 \pm 24.3$ & $72.1 \pm 19.3$ & $92 \pm 24.1 \neq \dagger$ & 0.27 & $<0.001$ & $<0.001$ \\
\hline PT/BW extension (\%) & $174.6 \pm 34.3$ & $176.4 \pm 23.3$ & $167 \pm 41.5$ & $195.8 \pm 43.6 \neq$ & 0.63 & 0.002 & 0.004 \\
\hline PT/BW flexion (\%) & $92.4 \pm 19.8$ & $89.5 \pm 19.1$ & $87.9 \pm 14.7$ & $116 \pm 30.1 \neq \dagger$ & 0.10 & 0.001 & $<0.001$ \\
\hline AVG power extension (watts) & $90 \pm 28$ & $92 \pm 27.3$ & $86.8 \pm 27$ & $110.6 \pm 31.8 \neq$ & 0.42 & $<0.001$ & $<0.001$ \\
\hline AVG power flexion (watts) & $50.2 \pm 21.2$ & $50.3 \pm 19.5$ & $47.7 \pm 14.2$ & $66.5 \pm 18.2 \neq \dagger$ & 0.25 & $<0.001$ & $<0.001$ \\
\hline \multicolumn{8}{|l|}{ Isokinetic endurance test } \\
\hline Total work extension (J) & $2673.8 \pm 960.3$ & $2660.5 \pm 895.2$ & $2744 \pm 783.8$ & $3171.2 \pm 1111.5$ & 0.37 & 0.09 & 0.08 \\
\hline Total work flexion $(J)$ & $1325.2 \pm 511.9$ & $1343.2 \pm 443.5$ & $1340.3 \pm 453.8$ & $1685 \pm 717.1$ f十 & 0.33 & 0.03 & 0.05 \\
\hline
\end{tabular}


Table 6 One-repetition maximum responses pre and post CART

\begin{tabular}{llll}
\hline 1-RM test & Pre $(N=21)$ & Post $(N=21)$ & $P$ value \\
\hline Lower body exercises & & & \\
Leg press & $127.6 \pm 21.9$ & $174.3 \pm 34.9$ & 0.0001 \\
Leg extension (right) & $41.3 \pm 14.2$ & $59.3 \pm 15.9$ & 0.003 \\
Leg extension (left) & $40.1 \pm 12.6$ & $58 \pm 16$ & 0.002 \\
Calf & $91.6 \pm 21.8$ & $131 \pm 27.5$ & 0.0002 \\
Seated leg curl (right) & $31.6 \pm 11.2$ & $43 \pm 11.5$ & 0.01 \\
Seated leg curl (left) & $31.9 \pm 10.8$ & $42 \pm 9.5$ & 0.021 \\
Upper body exercises & & & \\
Biceps & $10.6 \pm 2.2$ & $13.7 \pm 2.9$ & 0.005 \\
Flat bench press & $39 \pm 13$ & $52.7 \pm 15.1$ & 0.017 \\
Triceps & $97.4 \pm 20.7$ & 120.8 & 0.001 \\
Seated row & $62.5 \pm 18.2$ & $84.3 \pm 21.5$ & 0.010 \\
\hline Data are reported as means \pm SD. $P \leq 0.05$ & &
\end{tabular}

program composed by aerobic and resistance exercise with T2D in a randomized crossover protocol, which observed an increase of $12 \%$ in muscle strength [59]. However, Church et al. did not observe a significant improvement in peak torque and work in the combined training program after 9 months.

Sousa et al., in a RCT evaluated the impact of different exercise training modalities on functional fitness responses in apparently healthy older men, showing that only the combined exercise program was effective in improving all functional fitness components. It is noteworthy to point out they used long-term training (9 months) yet did not evaluate muscle strength [60].

Untrained individuals normally have rapid improvements in muscle strength during the initial phases of a training program, which are predominantly attributed to a learning effect as well as neuromuscular adaptations within the first 4 weeks of program initiation [61]. In this context, our results can be explained by true adaptations in muscle force production since the patients continued improving muscle strength throughout the program. These aspects are important given a recent study contrasting different ET protocols (i.e., aerobic versus resistance) observed that only resistance exercise had an important influence on maintaining reductions in $\mathrm{LDL}-\mathrm{C}, \mathrm{HbA} 1 \mathrm{C}$ and the increase in HDL-C, even if the training program is interrupted for a short term [62].

Resistance training have been highly recommended by the ACSM as an important tool to preserve/improve muscle mass and potentially improve insulin sensitivity, not only due to development of more muscle mass but also due to improved muscle quality $[63,64]$. Combining aerobic with resistance training, alternating the training each session can be an important alternative to preserve gains of functional capacity and muscle strength status.

In fact, it has been shown that the supervised aerobic, resistance or combined aerobic/resistance training are associated with greater decreases in HbAlc compared to exercise counseling alone or a singular training

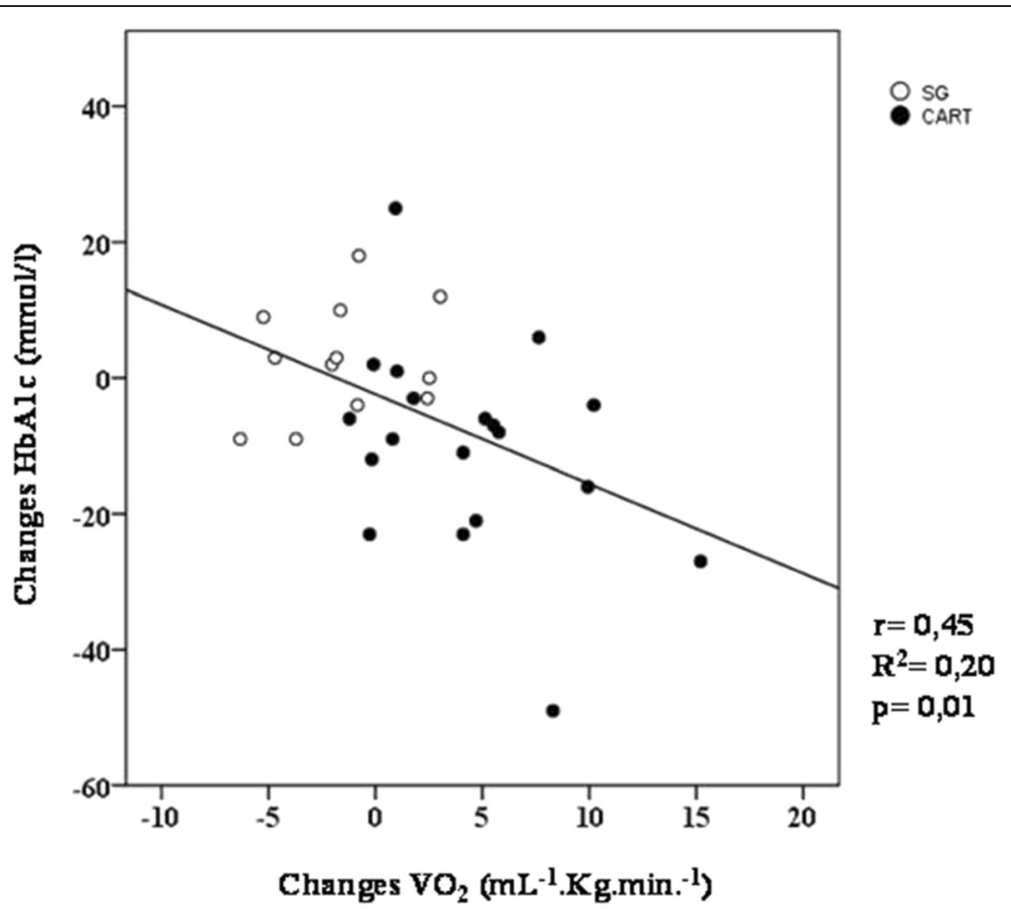

Fig. 2 Comparison between changes of $\mathrm{VO}_{2}\left(\mathrm{ml} \mathrm{kg}^{-1} \mathrm{~min}^{-1}\right)$ and changes $\mathrm{HbA} 1 \mathrm{c}(\mathrm{mmol} / \mathrm{mol})$ in response to 12 weeks of CART (filled circles) and sedentary (open circles) in diabetic patients 
Table 7 Pearson correlation between $\mathrm{HbA1c}$ post $X$ skinfold post

\begin{tabular}{lll}
\hline Skinfolds $(\mathrm{cm})$ & $\mathrm{HbA1c}$ & \\
\cline { 2 - 3 } & $P$ & 0.32 \\
\hline Triciptal & 0.04 & 0.33 \\
Biciptal & 0.04 & 0.53 \\
Subscapular & 0.0007 & 0.41 \\
Suprailiac & 0.01 & 0.39 \\
Abdominal & 0.01 & \\
\hline
\end{tabular}

Data are reported as mean \pm SD. $P \leq 0.05$

approach. Umpierre et al., in a systematic review with meta-regression analysis of RCTs, found that the chronic impact on glycemic control might be affected by volume and intensity of the structured exercise program and not only the mode of exercise training [65].

The main drawback of our study was the impossibility to use a gold standard assessment to diagnose autonomic function. This would have been valuable given T2D has a negative impact on the autonomic control. Assessing the effects of CART on autonomic function would have been of value and should be performed in future investigations. Another potential limitation was the impossibility to have a gold standard body composition assessment, such as DEXA. Thus, the inferences related to these assessments in our study must be confirmed by future investigations.

\section{Conclusions}

In conclusion, this study showed that a 12-week personalized and supervised concurrent ET program can improve not only the $\mathrm{VO}_{2}$ and muscle performance, but also glycemic control and body habitus. Future trials are necessary to contrast different approaches to CART, considering the effect on order of training program in the T2D population.

\section{Acknowledgements}

This study was supported by a Research Grant from CNPq (478789/2011-2) Conselho Nacional de Desenvolvimento Científico e Tecnológico - CNPq, Brazil, and Fundação de Amparo à Pesquisa do Estado de São Paulo, SP, Brazil - FAPESP 2009/01842-0.

\section{Funding}

Supported by a National Counsel of Technological and Scientific Development - CNPq and FAPESP n²009/01842-0

\section{Authors' Contributions}

$\mathrm{DB}$ researched the data and wrote the manuscript. $\mathrm{RC}$ researched the data and VMA reviewed the data. FCRC researched the data. RGM researched the data, contributed to the discussion, and reviewed/edited the manuscript. JCBJ researched the data. RA contributed to writing the manuscript, contributed to the discussion, and reviewed/edited the manuscript. ABS contributed to writing the manuscript, contributed to the discussion, and reviewed/edited manuscript. All authors read and approved the final manuscript.

\section{Competing Interests}

Daniela Bassi, Renata Gonçalves Mendes, Vivian Maria Arakelian, Flávia Cristina Rossi Caruso, Ramona Cabiddu, José Carlos Bonjorno Júnior, Ross Arena, Audrey Borghi-Silva declare that they have no conflict of interest.

\section{Author details \\ ${ }^{1}$ Cardiopulmonary Physiotherapy Laboratory, Physical Therapy Department, Federal University of Sao Carlos, Rodovia Washington Luis Km 235, Sao Carlos, SP, Brazil. 'Department of Interunits of Bioengineer, University of São Paulo, São Paulo, SP, Brazil. ${ }^{3}$ Department of Medicine, Federal University of São Carlos, São Paulo, SP, Brazil. ${ }^{4}$ Integrative Physiology Laboratory, College of Applied Health Sciences, University of Illinois Chicago, Chicago, IL, USA. ${ }^{5}$ Department of Physical Therapy, College of Applied Health Sciences, University of Illinois Chicago, Chicago, IL, USA.}

Received: 13 January 2016 Accepted: 20 July 2016

Published online: 11 August 2016

\section{References}

1. Schmidt MI, Duncan BB, Azevedo e Silva G, Menezes AM, Monteiro CA, Barreto SM, et al. Chronic non-communicable diseases in Brazil: burden and current challenges. Lancet. 2011;377:1949-61. Available from: http://www. sciencedirect.com/science/article/pii/S0140673611601359.

2. Chen L, Pei J-H, Kuang J, Chen H-M, Chen Z, Li Z-W, et al. Effect of lifestyle intervention in patients with type 2 diabetes: a meta-analysis. Metabolism. 2015;64:338-47. Available from: http://www.metabolismjournal.com/article/ S0026-0495(14)00312-6/pdf.

3. Colberg SR, Sigal RJ, Fernhall B, Regensteiner JG, Blissmer BJ, Rubin RR, et al. Exercise and type 2 diabetes: the American College of Sports Medicine and the American Diabetes Association: joint position statement executive summary. Diabetes Care. 2010;33:2692-6. Available from: http://www.ncbi. nlm.nih.gov/pmc/articles/PMC2992214/pdf/zdc2692.pdf.

4. Egan B, Zierath JR. Exercise metabolism and the molecular regulation of skeletal muscle adaptation. Cell Metab. 2013;17:162-84. Available from: http://www.sciencedirect.com/science/article/pii/S1550413112005037.

5. Lee AD, Hansen PA, Holloszy JO. Wortmannin inhibits insulin-stimulated but not contraction-stimulated glucose transport activity in skeletal muscle. FEBS Lett. 1995;361:51-4. Available from: http://onlinelibrary.wiley.com/doi/ 10.1016/0014-5793(95)00147-2/epdf.

6. DeFronzo RA, Jacot E, Jequier E, Maeder E, Wahren J, Felber JP. The effect of insulin on the disposal of intravenous glucose: results from indirect calorimetry and hepatic and femoral venous catheterization. Diabetes. 1981;30:1000-7. Available from: http://diabetes.diabetesjournals.org/content/30/12/1000.

7. Howald H, Hoppeler $\mathrm{H}$, Claassen $\mathrm{H}$, Mathieu O, Straub R. Influences of endurance training on the ultrastructural composition of the different muscle fiber types in humans. Pflügers Arch Eur J Physiol. 1985;403:369-76. Available from: http://www.ncbi.nlm.nih.gov/pubmed/4011389.

8. Phillips SM, Green HJ, Tarnopolsky MA, Heigenhauser GJ, Grant SM. Progressive effect of endurance training on metabolic adaptations in working skeletal muscle. Am J Physiol. 1996;270:E265-72. Available from: http://ajpendo.physiology.org/content/270/2/E265.

9. Vollaard NBJ, Constantin-Teodosiu D, Fredriksson K, Rooyackers O, Jansson E, Greenhaff $\mathrm{PL}$, et al. Systematic analysis of adaptations in aerobic capacity and submaximal energy metabolism provides a unique insight into determinants of human aerobic performance. J Appl Physiol. 2009;106:1479-86. Available from: http://jap.physiology.org/content/jap/106/5/1479.full.pdf.

10. Booth FW, Thomason DB. Molecular and cellular adaptation of muscle in response to exercise: perspectives of various models. Physiol Rev. 1991;71: 541-85. Available from: http://physrev.physiology.org/content/71/2/541.

11. Folland JP, Williams AG. The adaptations to strength training: morphological and neurological contributions to increased strength. Sports Med. 2007;37: 145-68. Available from: http://www.ncbi.n/m.nih.gov/pubmed/17241104

12. Kim TN, Park MS, Yang SJ, Yoo HJ, Kang HJ, Song W, et al. Prevalence and determinant factors of sarcopenia in patients with type 2 diabetes: the Korean Sarcopenic Obesity Study (KSOS). Diabetes Care. 2010;33:1497-9. Available from: http://care.diabetesjournals.org/content/diacare/33/7/1497.full.pdf.

13. Turner RC, Millns H, Neil HA, Stratton IM, Manley SE, Matthews DR, et al. Risk factors for coronary artery disease in non-insulin dependent diabetes mellitus: United Kingdom Prospective Diabetes Study (UKPDS: 23). BMJ. 1998;316:823-8. Available from: http://www.bmj.com/content/bmj/316/ 7134/823.full.pdf. 
14. Sigal RJ, Kenny GP, Boulé NG, Wells GA, Prud'homme D, Fortier M, et al. Effects of aerobic training, resistance training, or both on glycemic control in type 2 diabetes: a randomized trial. Ann Intern Med. 2007;147:357-69. Available from: http://annals.org/article.aspx?articleid=736439.

15. Church TS, Blair SN, Cocreham S, Johannsen N, Johnson W, Kramer K, et al. Effects of aerobic and resistance training on hemoglobin A1c levels in patients with type 2 diabetes: a randomized controlled trial. JAMA. 2010; 304:2253-62. Available from: http://www.ncbi.nlm.nih.gov/pmc/articles/ PMC3174102/pdf/nihms319307.pdf.

16. Schumann M, Yli-Peltola K, Abbiss CR, Häkkinen K. Cardiorespiratory adaptations during concurrent aerobic and strength training in men and women. PLoS One. 2015;10:e0139279. Available from: http://journals.plos. org/plosone/article/asset?id=10.1371\%2Fjournal.pone.0139279.PDF.

17. Wilson JM, Marin PJ, Rhea MR, Wilson SMC, Loenneke JP, Anderson JC. Concurrent training: a meta-analysis examining interference of aerobic and resistance exercises. J Strength Cond Res. 2012;26:2293-307. Available from: http://www.ncbi.nlm.nih.gov/pubmed/22002517.

18. Nelson AG, Arnall DA, Loy SF, Silvester LJ, Conlee RK. Consequences of combining strength and endurance training regimens. Phys Ther. 1990;70: 287-94. Available from: http://ptjournal.apta.org/content/ptjournal/70/5/287. full.pdf.

19. Owen N, Healy GN, Matthews CE, Dunstan DW. Too much sitting: the population health science of sedentary behavior. Exerc Sport Sci Rev. 2010; 38:105-13. Available from: http://www.medscape.com/viewarticle/725341_5.

20. Vinik Al, Ziegler D. Diabetic cardiovascular autonomic neuropathy. Circulation. 2007;115:387-97. Available from: http://circ.ahajournals.org/ content/115/3/387.

21. de SP RLC, Sá de JR, Chacra AR, Dib SA. Diabetic cardiovascular autonomic neuropathy: risk factors, clinical impact and early diagnosis. Arq Bras Cardiol. 2008;90:e24-31. Available from: http://www.scielo.br/ pdf/abc/v90n4/en_v90n4a14.pdf.

22. Bredella MA, Utz AL, Torriani M, Thomas B, Schoenfeld DA, Miller KK, Anthropometry CT, DXA as predictors of GH deficiency in premenopausal women. ROC curve analysis. J Appl Physiol. 2008;106:418-22. Available from: http://jap.physiology.org/content/106/2/418.full.pdf+html.

23. Jensky-Squires NE, Dieli-Conwright CM, Rossuello A, Erceg DN, McCauley S, Schroeder ET. Validity and reliability of body composition analysers in children and adults. Br J Nutr. 2008;100:859-65. Available from: http:// journals.cambridge.org/download.php?file=\%2FBJN\%2FBJN100_04\%2FS000 7114508925460a.pdf\&code $=$ d06148b8e4ffca977fc0936b8a4b398c.

24. Lukaski HC, Bolonchuk WW, Hall CB, Siders WA. Validation of tetrapolar bioelectrical impedance method to assess human body composition. J Appl Physiol. 1986;60:1327-32. Available from: http://jap.physiology.org/content/ 60/4/1327.full.pdf.

25. Suh S-H, Paik I-Y, Jacobs K. Regulation of blood glucose homeostasis during prolonged exercise. Mol Cells. 2007;23:272-9. Available from: http://www. molcells.org/journal/download_pdf.php?spage=272\&volume=23\&number=3.

26. Houmard JA. Effect of the volume and intensity of exercise training on insulin sensitivity. J Appl Physiol. 2003;96:101-6. Available from: http://jap. physiology.org/content/jap/96/1/101.full.pdf.

27. LE Neder JAN. Teste de Exercício Cardiopulmonar. J Pneumol. 2002;28:166-206.

28. Buchfuhrer MJ, Hansen JE, Robinson TE, Sue DY, Wasserman K, Whipp BJ. Optimizing the exercise protocol for cardiopulmonary assessment. J Appl Physiol. 1983;55:1558-64. Available from: http://jap.physiology. org/content/55/5/1558.

29. Guazzi M, Arena R. CardioPulse. New clinical cardiopulmonary exercise testing joint statement from the European Society of Cardiology and American Heart Association. Eur Heart J. 2012;33:2627-8. Available from: http://www.escardio.org/The-ESC/Communities/European-Association-forCardiovascular-Prevention-\&-Rehabilitation-(EACPR)/News/ClinicalCardiopulmonary-Exercise-Testing-New-EACPR-AHA-Joint-Statement.

30. Myers J, de Souza CR, Borghi-Silva A, Guazzi M, Chase P, Bensimhon D, et al. A neural network approach to predicting outcomes in heart failure using cardiopulmonary exercise testing. Int J Cardiol. 2014;171:265-9. Available from: http://www.internationaljournalofcardiology.com/article/S01675273(13)02241-9/pdf

31. Borghi-Silva A, Di Thommazo L, Pantoni CBF, Mendes RG, Salvini TDF, Costa D. Non-invasive ventilation improves peripheral oxygen saturation and reduces fatigability of quadriceps in patients with COPD. Respirology. 2009;14:537-44. Available from: http://onlinelibrary.wiley.com/doi/10.1111/j.1440-1843.2009. 01515.x/pdf
32. Wilborn C, Greenwood M, Wyatt F, Bowden RGD. The effects of exercise intensity and body position on cardiovascular variables during resistance exercise. JEP Online. 2004;7:29-36.

33. Donnelly JE, Blair SN, Jakicic JM, Manore MM, Rankin JW, Smith BK, American College of Sports Medicine Position Stand. Appropriate physical activity intervention strategies for weight loss and prevention of weight regain for adults. Med Sci Sports Exerc. 2009;41:459-71. Available from: http://journals.Iww.com/acsm-msse/pages/articleviewer.aspx?year=2009\& issue $=02000 \&$ article $=00026 \&$ type $=$ abstract.

34. Sigal RJ, Kenny GP, Wasserman DH, Castaneda-Sceppa C, White RD. Physical activity/exercise and type 2 diabetes: a consensus statement from the American Diabetes Association. Diabetes Care. 2006;29:1433-8. Available from: http://care.diabetesjournals.org/content/diacare/29/6/1433.full.pdf.

35. Belli T, Ribeiro LFP, Ackermann MA, Baldissera V, Gobatto CA, Galdino da Silva R. Effects of 12-week overground walking training at ventilatory threshold velocity in type 2 diabetic women. Diabetes Res Clin Pract. 2011;93:337-43. Available from: http://www.diabetesresearchclinical practice.com/article/S0168-8227(11)00234-8/pdf.

36. Taylor R. Interpretation of the correlation coefficient: a basic review. J Diagnostic Med Sonogr. 1990;6:35-9. Available from: http://www. diabetesresearchclinicalpractice.com/article/S0168-8227(11)00234-8/pdf.

37. Tagougui S, Leclair E, Fontaine P, Matran R, Marais G, Aucouturier J, et al. Muscle oxygen supply impairment during exercise in poorly controlled type 1 diabetes. Med Sci Sports Exerc. 2015;47:231-9. Available from: http://www. ncbi.nlm.nih.gov/pmc/articles/PMC4323553/pdf/mss-47-231.pdf.

38. Myers J, Prakash M, Froelicher V, Do D, Partington S, Atwood JE. Exercise capacity and mortality among men referred for exercise testing. N Engl J Med. 2002;346:793-801. Available from: http://www.nejm.org/doi/pdf/10. 1056/NEJMoa011858.

39. Vinetti G, Mozzini C, Desenzani P, Boni E, Bulla L, Lorenzetti I, et al. Supervised exercise training reduces oxidative stress and cardiometabolic risk in adults with type 2 diabetes: a randomized controlled trial. Sci Rep. 2015;5:9238. Available from: http://www.nature.com/articles/srep09238.

40. Johannsen NM, Swift DL, Lavie CJ, Earnest CP, Blair SN, Church TS. Categorical analysis of the impact of aerobic and resistance exercise training, alone and in combination, on cardiorespiratory fitness levels in patients with type 2 diabetes: results from the HART-D study. Diabetes Care. 2013;36:3305-12. Available from: http://www.ncbi.nlm.nih.gov/pmc/ articles/PMC3781553/pdf/3305.pdf.

41. Pimenta NM, Santa-Clara H, Sardinha LB, Fernhall B. Body fat responses to a 1-year combined exercise training program in male coronary artery disease patients. Obesity (Silver Spring). 2013;21:723-30. Available from: http://www. ncbi.nlm.nih.gov/pmc/articles/PMC3781553/pdf/3305.pdf.

42. Johannsen NM, Sparks LM, Zhang Z, Earnest CP, Smith SR, Church TS, et al. Determinants of the changes in glycemic control with exercise training in type 2 diabetes: a randomized trial. PLoS One. 2013;8:e62973. Available from: http://journals.plos.org/plosone/article/asset?id=10.1371\%2Fjournal. pone.0062973.PDF.

43. Physical activity guidelines for diabetes [Internet]. [cited 2015 Nov 23] Available from: https://www.ihs.gov/MedicalPrograms/Diabetes/HomeDocs/ Training/WebBased/PhysicalActivity2/Transcript_PhyActivity2_508c.pdf

44. Boulé NG, Haddad E, Kenny GP, Wells GA, Sigal RJ. Effects of exercise on glycemic control and body mass in type 2 diabetes mellitus: a meta-analysis of controlled clinical trials. JAMA. 2001;286:1218-27. Available from: http:// jama.jamanetwork.com/article.aspx?articleid=194184.

45. Sacks DB, Bruns DE, Goldstein DE, Maclaren NK, McDonald JM, Parrott M. Guidelines and recommendations for laboratory analysis in the diagnosis and management of diabetes mellitus. Clin Chem. 2002;48:436-72. Available from: http://care.diabetesjournals.org/content/diacare/34/6/e61.full.pdf.

46. Castaneda C, Layne JE, Munoz-Orians L, Gordon PL, Walsmith J, Foldvari M, et al. A randomized controlled trial of resistance exercise training to improve glycemic control in older adults with type 2 diabetes. Diabetes Care. 2002;25:2335-41. Available from: http://care.diabetesjournals.org/ content/diacare/25/12/2335.full.pdf.

47. Liu Y, Liu S-X, Cai Y, Xie K-L, Zhang W-L, Zheng F. Effects of combined aerobic and resistance training on the glycolipid metabolism and inflammation levels in type 2 diabetes mellitus. J Phys Ther Sci. 2015;27: 2365-71. Available from: http://www.ncbi.nlm.nih.gov/pmc/articles/ PMC4540883/pdf/jpts-27-2365.pdf.

48. Nathan DM, Kuenen J, Borg R, Zheng H, Schoenfeld D, Heine RJ. Translating the A1C assay into estimated average glucose values. Diabetes Care. 2008;31: 
1473-8. Available from: http://care.diabetesjournals.org/content/diacare/31/8/ 1473.full.pdf

49. Selvin E, Marinopoulos S, Berkenblit G, Rami T, Brancati FL, Powe NR, et al. Meta-analysis: glycosylated hemoglobin and cardiovascular disease in diabetes mellitus. Ann Intern Med. 2004;141:421-31. Available from: http://annals.org/article.aspx?articleid=717820.

50. The International Expert Committee. International Expert Committee report on the role of the A1C assay in the diagnosis of diabetes. Diabetes Care. 2009;32:1327-34. Available from: http://care.diabetesjournals.org/content/ diacare/32/7/1327.full.pdf.

51. Gray A, Raikou M, McGuire A, Fenn P, Stevens R, Cull C, et al. Cost effectiveness of an intensive blood glucose control policy in patients with type 2 diabetes: economic analysis alongside randomised controlled trial (UKPDS 41). United Kingdom Prospective Diabetes Study Group. BMJ. 2000; 320:1373-8. Available from: http://www.bmj.com/content/bmj/320/7246/ 1373.full.pdf.

52. Vergès $B$, Patois-Vergès $B$, Iliou $M-C$, Simoneau-Robin I, Bertrand $\mathbf{J}-\mathrm{H}$, Feige J-M, et al. Influence of glycemic control on gain in VO2 peak, in patients with type 2 diabetes enrolled in cardiac rehabilitation after an acute coronary syndrome. The prospective DARE study. BMC Cardiovasc Disord. 2015;15:64. Available from: http://www.ncbi.nlm.nih.gov/pmc/ articles/PMC4495681/pdf/12872_2015_Article_55.pdf.

53. Awotidebe TO, Adedoyin RA, Yusuf AO, Mbada CE, Opiyo R, Maseko FC. Comparative functional exercise capacity of patients with type 2-diabetes and healthy controls: a case control study. Pan Afr Med J. 2014;19:257. Available from: http://www.ncbi.n/m.nih.gov/pmc/articles/PMC4382056/pdf/ PAMJ-19-257.pdf.

54. Sénéchal M, Swift DL, Johannsen NM, Blair SN, Earnest CP, Lavie CJ, et al Changes in body fat distribution and fitness are associated with changes in hemoglobin A1c after 9 months of exercise training: results from the HARTD study. Diabetes Care. 2013;36:2843-9. Available from: http://care. diabetesjournals.org/content/diacare/36/9/2843.full.pdf.

55. Ryan AS, Pratley RE, Elahi D, Goldberg AP. Changes in plasma leptin and insulin action with resistive training in postmenopausal women. Int J Obes Relat Metab Disord. 2000;24:27-32. Available from: http://www.ncbi.nlm.nih. gov/pubmed/10702747.

56. Larose J, Sigal RJ, Khandwala F, Prud'homme D, Boulé NG, Kenny GP. Associations between physical fitness and $\mathrm{HbA}_{1}(\mathrm{c})$ in type 2 diabetes mellitus. Diabetologia. 2011;54:93-102. Available from: http://link.springer. com/article/10.1007/s00125-010-1941-3.

57. Egger A, Niederseer D, Diem G, Finkenzeller T, Ledl-Kurkowski E, Forstner $\mathrm{R}$, et al. Different types of resistance training in type 2 diabetes mellitus: effects on glycaemic control, muscle mass and strength. Eur J Prev Cardiol. 2013;20:1051-60. Available from: http://cpr. sagepub.com/content/20/6/1051.full.pdf+html.

58. Cauza E, Strehblow C, Metz-Schimmerl S, Strasser B, Hanusch-Enserer U, Kostner $\mathrm{K}$, et al. Effects of progressive strength training on muscle mass in type 2 diabetes mellitus patients determined by computed tomography. Wien Med Wochenschr. 2009;159:141-7. Available from: http://link.springer. com/article/10.1007\%2Fs10354-009-0641-4.

59. Maiorana A, O'Driscoll G, Goodman C, Taylor R, Green D. Combined aerobic and resistance exercise improves glycemic control and fitness in type 2 diabetes. Diabetes Res Clin Pract. 2002:56:115-23. Available from: http://www. diabetesresearchclinicalpractice.com/article/S0168-8227(01)00368-0/pdf.

60. Sousa N, Mendes R, Abrantes C, Sampaio J, Oliveira J. Effectiveness of combined exercise training to improve functional fitness in older adults: a randomized controlled trial. Geriatr Gerontol Int. 2014;14:892-8. Available from: http://onlinelibrary.wiley.com/doi/10.1111/ggi.12188/pdf.

61. Staron RS, Leonardi MJ, Karapondo DL, Malicky ES, Falkel JE, Hagerman FC, et al. Strength and skeletal muscle adaptations in heavy-resistance-trained women after detraining and retraining. J Appl Physiol. 1991;70:631-40. Available from: http://jap.physiology.org/content/70/2/631.

62. Yuing Farias T, Santos-Lozano A, Solís Urra P, Cristi-Montero C. effects of training and detraining on glycosylated haemoglobin, glycaemia and lipid profile in type-ii diabetics. Nutr. Hosp. [Internet]. [cited 2015 Nov 25];32: 1729-34. Available from: http://www.aulamedica.es/nh/pdf/9341.pdf.

63. Pollock ML, Franklin BA, Balady GJ, Chaitman BL, Fleg JL, Fletcher B, et al. Resistance exercise in individuals with and without cardiovascular disease: benefits, rationale, safety, and prescription: an advisory from the Committee on Exercise, Rehabilitation, and Prevention, Council on Clinical Cardiology,
American Heart Association. Circulation. 2000;101:828-33. Available from: http://circ.ahajournals.org/content/101/7/828.full.

64. Dela F, Kjaer M. Resistance training, insulin sensitivity and muscle function in the elderly. Essays Biochem. 2006;42:75-88. Available from: http://essays. biochemistry.org/content/ppebio/42/75.full.pdf.

65. Umpierre D, Ribeiro PAB, Kramer CK, Leitão CB, Zucatti ATN, Azevedo MJ, et al. Physical activity advice only or structured exercise training and association with $\mathrm{HbA} 1 \mathrm{c}$ levels in type 2 diabetes: a systematic review and meta-analysis. JAMA. 2011;305:1790-9. Available from: http://www.ncbi.nlm. nih.gov/pubmedhealth/PMH0031815/.

\section{Submit your manuscript to a SpringerOpen ${ }^{\circ}$ journal and benefit from:}

- Convenient online submission

- Rigorous peer review

- Immediate publication on acceptance

- Open access: articles freely available online

- High visibility within the field

- Retaining the copyright to your article

Submit your next manuscript at $>$ springeropen.com 